\title{
Fabrication of 9,9'-Bis(aryl)fluorene-modified Nanocellulose Bamboo Fiber Composite
}

\author{
Khan Md Sefat, ${ }^{\mathrm{a}}$ Takashi Kurose, ${ }^{\mathrm{b}}$ Masahiro Yamada, ${ }^{\mathrm{c}}$ Hiroshi Ito, ${ }^{\mathrm{b}, \mathrm{d}}$ and \\ Shinichi Shibata ${ }^{\mathrm{a}, *}$
}

\begin{abstract}
A green composite was fabricated using bamboo fiber and 9,9'bis(aryl)fluorene-modified cellulose nanofiber (FCNF). Cellulose nanofiber (CNF) and finely crushed bamboo fiber (CBF) were also used as binders. The mechanical properties of the composites were compared. It was found that the FCNF-bamboo fiber composite had the maximum flexural strength among these binders. This result was likely due to strong bonding by chemical reactions among fibers and the FCNF. The effect of fiber orientation accuracy on the mechanical properties of the composites was also investigated. When the bamboo fibers were carefully aligned, without fibers crossing each other, the mechanical properties increased by two times, compared to the composites with fibers crossing each other. In the accurately aligned bamboo composites, the cross sections of the fibers were largely deformed by compression stress during hot-press forming. Thus, the gaps among fibers decreased, and interfacial adherence was improved. The effect of fabrication temperature on the mechanical properties of the FCNF-bamboo composite was also examined. It was found that the maximum flexural modulus and strength of the composites were at approximately $250{ }^{\circ} \mathrm{C}$, and the mechanical properties rapidly decreased above $270^{\circ} \mathrm{C}$ due to thermal degradation of the bamboo fiber.
\end{abstract}

Keywords: Bamboo fiber; 9,9'-Bis(aryl)fluorene-modified nanocellulose; Green composite; Flexural properties

Contact information: a: Faculty of Engineering, Material Processing Laboratory, University of the Ryukyus, Nishihara 903-0213, Okinawa, Japan; b: Research Center for Green Materials and Advanced Processing, Yamagata University, 4-3-16 Jonan, Yonezawa, Yamagata 992-8510, Japan; c: Energy Technology Laboratories, Osaka Gas. Co. Ltd., 6-19-9 Torishima, Konohana-ku, Osaka 554-0051, Japan; d: Department of Organic Materials Science, Graduate School of Organic Materials Science, Yamagata University, 4-3-16 Jonan, Yonezawa, Yamagata 992-8510, Japan;

*Corresponding author: shibata@tec.u-ryukyu.ac.jp

\section{INTRODUCTION}

This work focuses on developing high performance composite materials, while minimizing the usage of synthetic polymer, following a previous study of composite materials (Shibata et al. 2008). Recently, fiber-reinforced composite materials have obtained commercial success in structural applications such as interior parts of automobiles and aircraft, where there is a need to increase fuel efficiency by reducing weight. Carbon fiber composites have the potential to reduce the weight of aircraft components by up to $40 \%$ compared to light metal alloys. The Airbus A380 and Boeing 787 Dreamliner are examples where composites have replaced metal alloys by at least $25 \%$ of structural mass (Beck et al. 2011). 
Applications of fiber-reinforced composites are increasing and include sporting goods, electronics, and various home appliances. These composites are also being studied as promising in orthopedic medicine and prosthetic devices (Scholz et al. 2011). Natural fibers and synthetic polymers as composites have also been applied in automobile parts, cell-phones, etc. (Sun 2018).

Previous studies attempted to develop natural fiber composites (polypropylenebagasse fibers), as a tentative approach to minimizing recycling, eventually reducing the carbon footprint. One discouraging fact while dealing with these materials is disposal management. Practically and on a large scale, it is infeasible to separate each component from the composites. Incinerators are severely affected while treating these waste products. Most importantly, some toxic gases of the $\mathrm{NO}_{\mathrm{x}}$ group are emitted into the environment by this process. Hence, there came the idea to study and develop fully bio-based green composites, with a goal of high mechanical performance. Polymer composites made of natural fibers and biopolymers are considered green composites (Shekar and Ramachandra 2018; Netravali 2019).

There are abundant sources of fibers (bagasse, bamboo, coir, flax, hemp, jute, sisal, etc.) in nature that have been used from the ancient period. Bamboo, one of the fastgrowing grasses in tropical and subtropical regions, with high inherent strength (tensile strength of 300 to $600 \mathrm{MPa}$ and tensile modulus of 20 to $50 \mathrm{GPa}$ (Amada et al. 1997; Takagi and Takeichi 2012)) and temperature stability was selected for this investigation. In modern society, natural fibers have been replaced by synthetic polymers because of greater utility, function, and mechanical performance. Concerns about climatic change have reinvigorated the economic value of natural fibers.

Biodegradable resins such as poly(lactic acid) (PLA) and polyhydroxyalkanoate (PHA) are interesting as matrices for bio-composites (Sun 2018). However, to widen the matrix selection, it is an interesting research area to discover alternative matrices with better adhesion, binding capability, and interfacial strength. Takagi and Takeichi (2012) developed bamboo-fiber-reinforced binderless green composite using bamboo fiber and steam-exploded bamboo powder. Imanishi et al. (2005) fabricated wood powder composites without adhesive and found that moisture was needed to produce wood powder composites with high bending strength. Nishino et al. (2004) and Nishino and Arimoto (2007) demonstrated all-cellulose composites using unidirectional ramie fibers with cellulose binder by N,N'-dimethylacetamide pre-treatment.

From previous experiments conducted in the authors' laboratory, it was learned that unidirectionally oriented fiber composite presents more than 2.5 times higher flexural strength than that of randomly oriented fiber, specifically for bamboo and kenaf composites (Shibata et al. 2008). Therefore, the unidirectionally fiber orientation composite was selected in this investigation.

The 9,9'-bis(aryl)fluorene, holding cardo moieties in its bulky steric structure, possesses high dispersibility and compatibility with resins (Sugimoto et al. 2019). It has potential to act as a binder in green composites due to its functional group. Learning from the aforementioned findings, a 9,9'-bis(aryl)fluorene-modified cellulose nanofiber (FCNF)-bamboo fiber composite was developed. The FCNF was used as a binder and compared with cellulose nanofiber $(\mathrm{CNF})$ and finely crushed bamboo fiber $(\mathrm{CBF})$. Additionally, optimal fiber alignment and press forming temperature in bamboo composite fabrication were evaluated.

Sefat et al. (2021). "Bis(aryl)fluorene CNF composite," BioResources 16(2), 3907-3915. 3908 


\section{EXPERIMENTAL}

\section{Materials and Methods}

Bamboo culms in this study were obtained in the west local area of Tokushima Prefecture in Japan. The lower part of the bamboo, below approximately $2 \mathrm{~m}$ of the $15 \mathrm{~m}$ height, was used. The culm was cut to $22 \mathrm{~cm}$ in length, excluding the joint part, and the epidermis covering its stem was peeled off. In the cross-section view, the culm was cut into 16 pieces of radially symmetrical shape. Each piece was boiled with $3 \% \mathrm{NaOH}$ at 80 ${ }^{\circ} \mathrm{C}$ for $2 \mathrm{~h}$ in a flask. The fiber bundles were separated by hand after the alkali treatment, as shown in Fig. 1(a). These separated fibers were $22 \mathrm{~cm}$ in length and $0.2 \mathrm{~mm}$ to $0.5 \mathrm{~mm}$ in diameter. Each fiber consisted of small fibers of approximately $0.01 \mathrm{~mm}$ to $0.015 \mathrm{~mm}$ in diameter. Thus, these were fiber bundles, strictly; however, these fiber bundles are simply referred to as bamboo fibers hereafter.

Three types of binders were prepared. The FCNF and CNF were supplied by Osaka Gas Chemical Co., Ltd (Osaka, Japan). Finely crushed bamboo fiber (CBF) was obtained by crushing bamboo fibers with an electric juicer/mixer after alkali treatment. Each binder was adjusted to a dilution weight ratio of 1:99 by ion-exchanged water and mixed by a mechanical homogenizer at $8000 \mathrm{rpm}$ for $20 \mathrm{~min}$ to obtain a homogeneous binder suspension.

The FCNF used was the same material reported by Sugimoto et al. (2019). The synthesis process is shown in Fig. 2. A highly reactive primary hydroxyl group at C6position of a glucose unit is supposed to react with BPFG (bisphenol fluorene diglycidyl ether) in DBU (1,8-diazabicyclo[5.4.0]undec-7-ene). The hydroxy group at C6-position is attacked by the epoxy group of BPFG and formed ether bonds. The modification rate DS, which is the ratio of BPFG in one glucose unit, has been evaluated by FT-IR using a standard curve method. The aromatic ring deformation at $1506 \mathrm{~cm}^{-1}$ was characteristic of fluorene aromatic rings. As a result, the modification degree of substitution was DS=0.048.

Hot-pressed specimens were prepared as follows: Bamboo fibers (20 g) were carefully aligned side by side, with the fibers being unidirectional, and in one layer on a stainless steel tray, as shown in Fig. 1(b). The abovementioned binder suspension was poured onto these aligned fibers, and the tray was dried by an electric oven at $80{ }^{\circ} \mathrm{C}$ for 24 h.
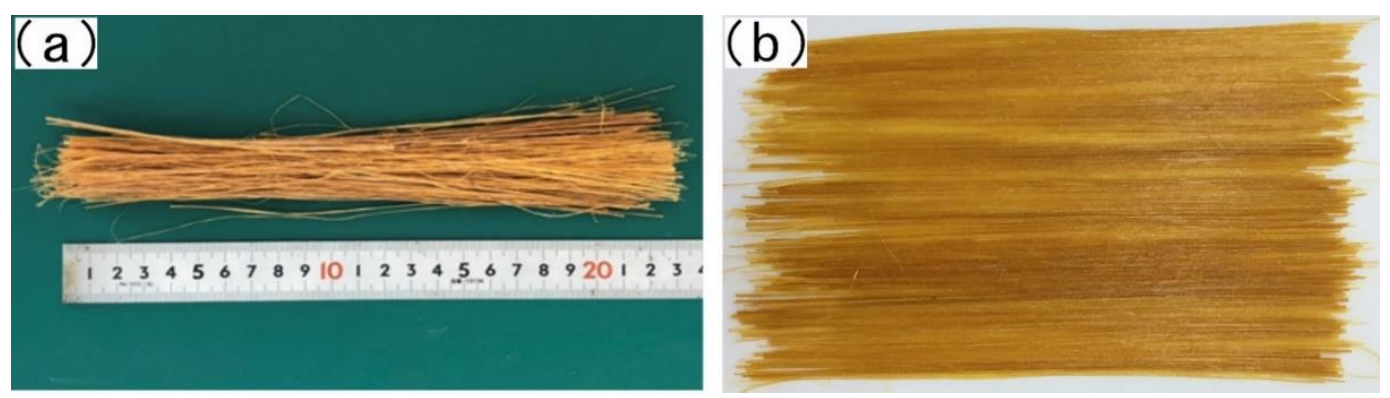

Fig. 1. (a) Natural bamboo fibers obtained after alkali treatment and (b) unidirectionally aligned bamboo fibers side by side in one layer before binder coating

The dried sheets of bamboo fibers and binders were laminated between stainless steel plates, as shown in Fig. 3, and hot-pressed at a pressure of $10 \mathrm{MPa}$ for $5 \mathrm{~min}$ at 230 ${ }^{\circ} \mathrm{C}$. After that, the laminated specimen was cut to $13 \mathrm{~mm}$ in width and $29 \mathrm{~mm}$ in length for flexural testing. 

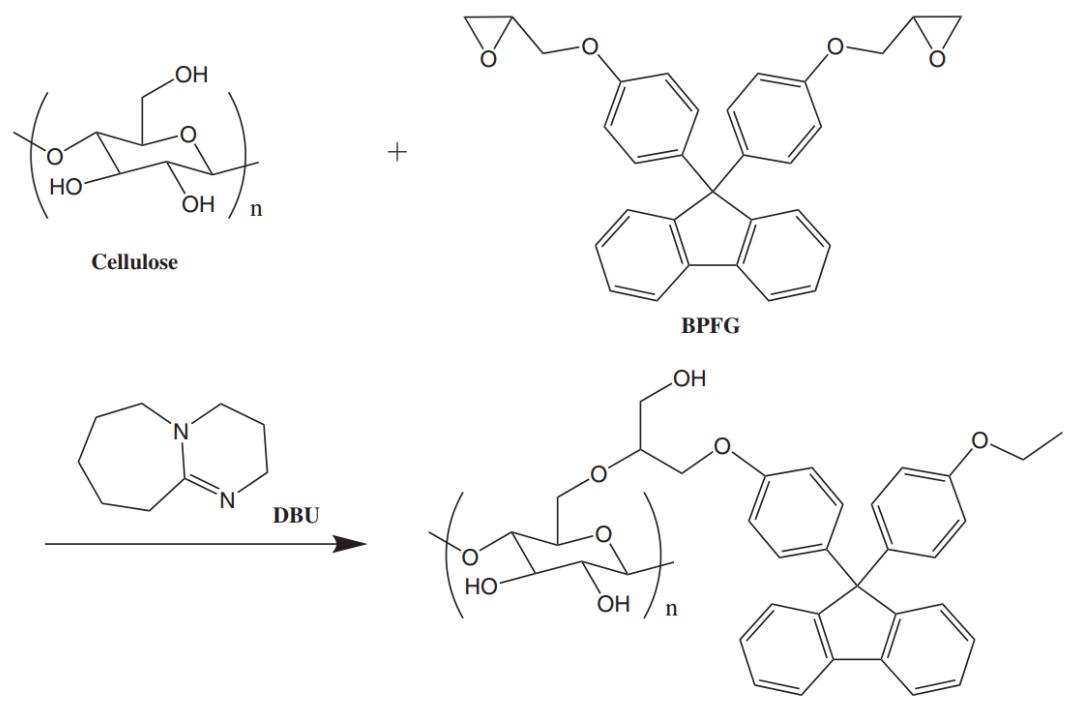

FCNF

Fig. 2. Modification of cellulose by BPFG with DBU solvent

Microstructural observations were conducted at both the microscale and macroscale. A scanning electron microscope / energy dispersive X-ray spectrometer (TM3030, Hitachi, Tokyo, Japan) was used for micro-observation. A digital microscope (VHX-950F, Keyence, Osaka, Japan) was used for macro-observation. The stacked specimen was cut to $10 \mathrm{~mm}$ length, and this specimen was embedded in epoxy so that the cross section could be observed. The surface was polished until obtaining a mirror surface.

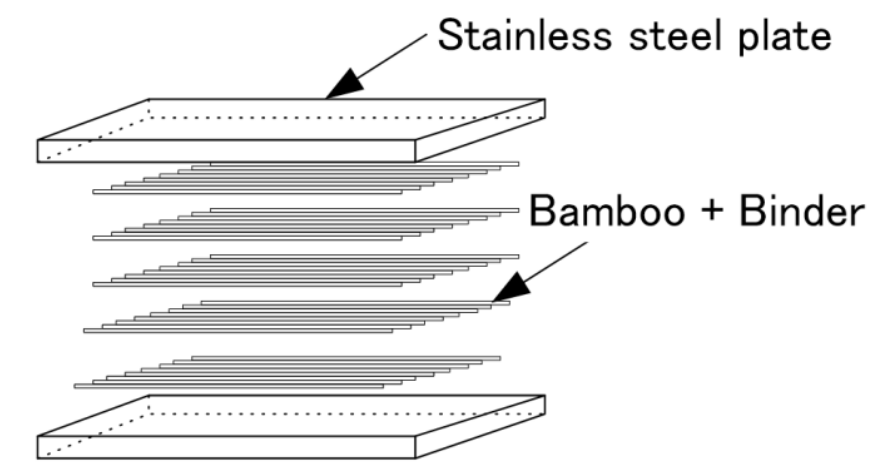

Fig. 3. Schematic illustration of bamboo-binder hot-press forming

The flexural testing was performed according to ISO 178 (2010) at each condition with three specimens using a universal testing machine (Shimadzu EZ Test, Kyoto, Japan). The test used a span length of $22 \mathrm{~mm}$ and a crosshead speed of $1 \mathrm{~mm} / \mathrm{min}$. The specimens used in the flexural test were $29 \mathrm{~mm}$ in length, $13 \mathrm{~mm}$ in width, and $1.0 \mathrm{~mm}$ to $1.5 \mathrm{~mm}$ in thickness. The flexural modulus was determined by the initial derivative line of the loaddisplacement curve. The highest inclination line was obtained as the initial derivative line between $0 \%$ and $15 \%$ of the maximum load. The flexural strength was calculated using the maximum load. 


\section{RESULTS AND DISCUSSION}

Figure 4 shows the flexural modulus and strength values of the $10 \%$ binder-bamboo composites. The combination of FCNF-bamboo exhibited better mechanical properties than the other two types of binders.

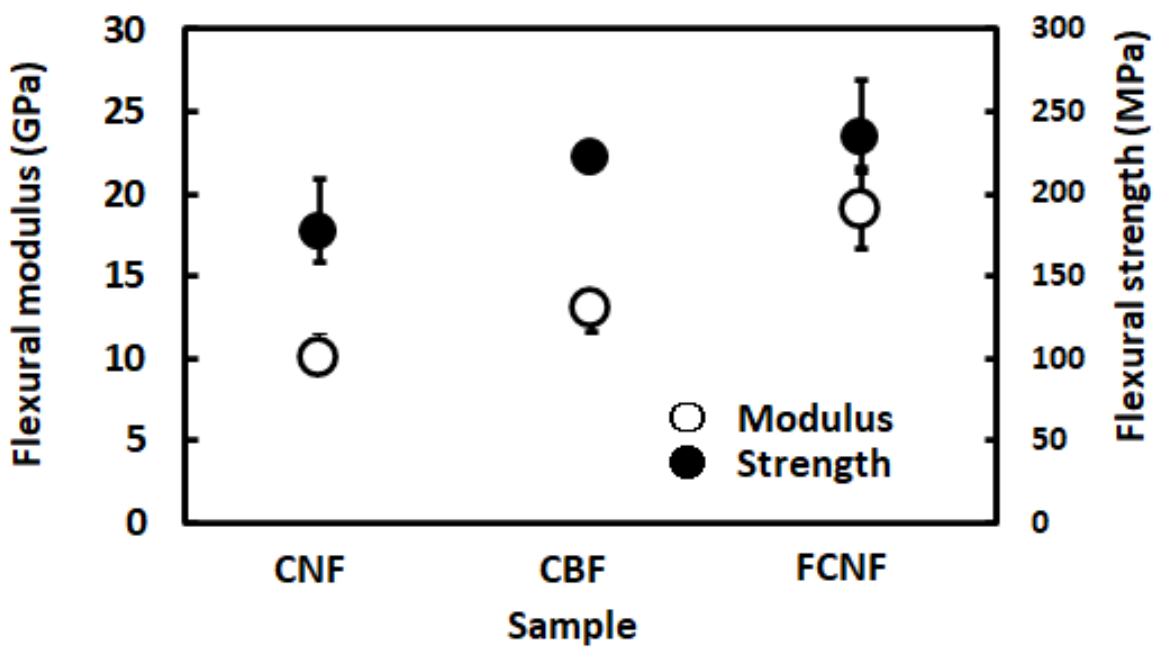

Fig. 4. Flexural modulus and strength values of the FCNF-bamboo, CBF-bamboo, and CNFbamboo composites

Figure 5 presents the relationships between load and displacement in the flexural tests. In the FCNF-bamboo composite, the bamboo fibers were broken at the top of the curve in the graph. In the CNF-bamboo composites, delamination among the layers started at the top of the curve. Figure 6 shows the surface appearances of the FCNF and CNF composites just after hot-press forming at $230^{\circ} \mathrm{C}$. The fibers that were coated by $\mathrm{CNF}$ were not all bonded, and some separated from each other, as shown in Fig. 6(a). Meanwhile, the fibers and binder were bonded by FCNF, as shown in Fig. 6(b). This result is likely due to the FCNF having epoxy functional groups, which reacted both with each other and with cellulose hydroxy groups.

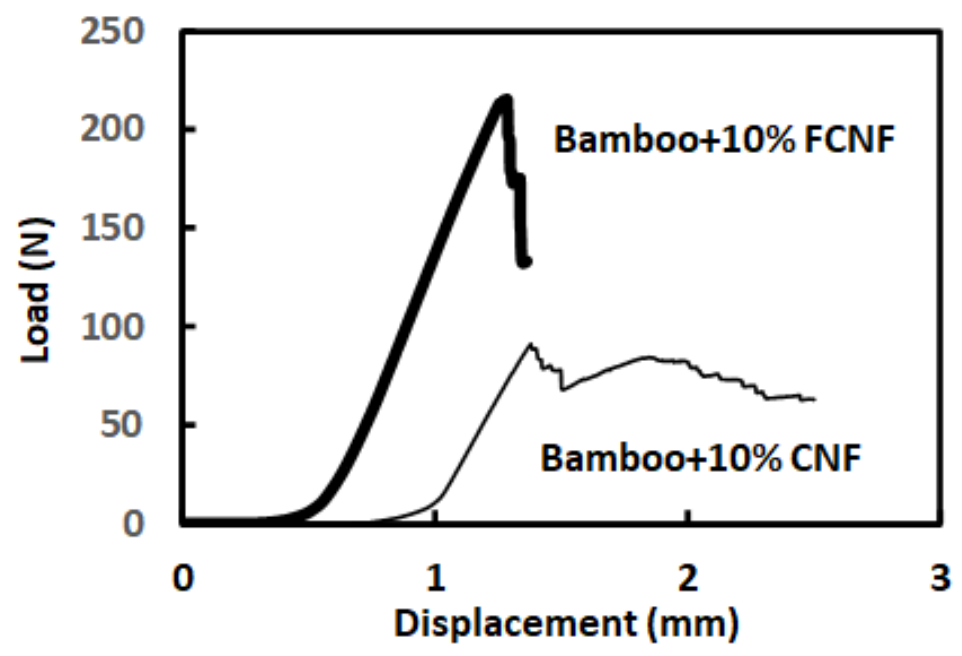

Fig. 5. Relationship between displacement and load in flexural tests 

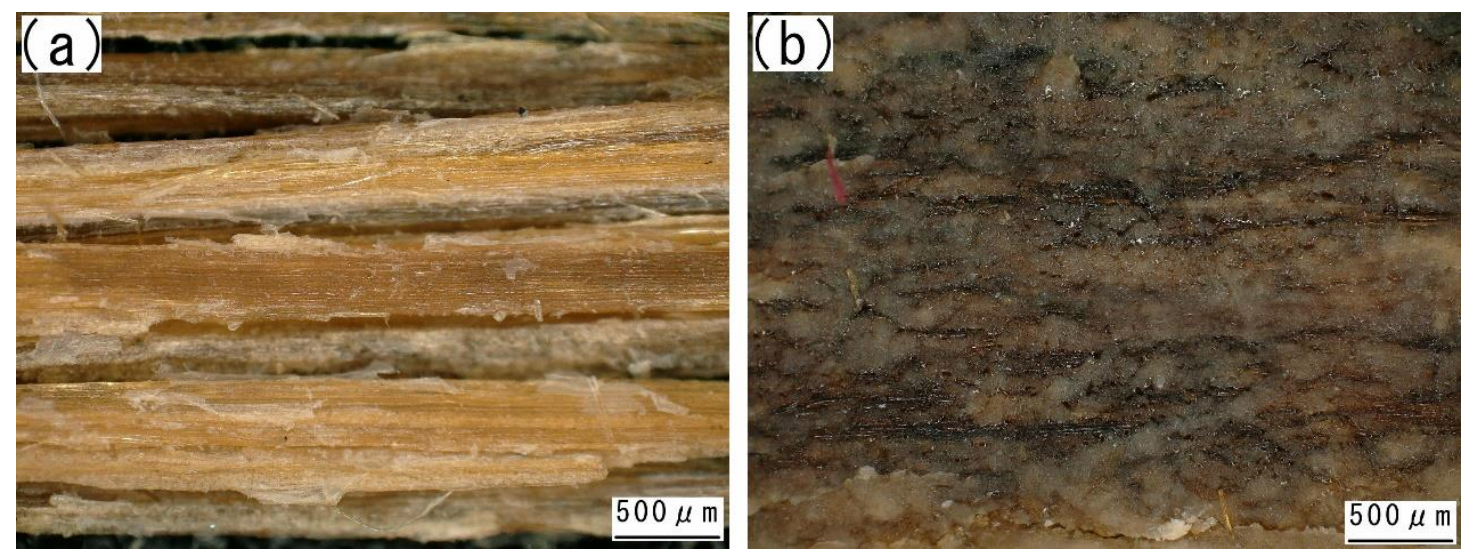

Fig. 6. Macro-observation photographs of (a) CNF-bamboo composite and (b) FCNF-bamboo composite

Figure 7 shows the comparison of flexural modulus and strength values between the heterogeneously aligned bamboo fiber composites and the homogeneously aligned one. As shown, both the flexural modulus and flexural strength of the homogeneously aligned bamboo fiber composites were two times higher than those of the heterogeneously aligned composites.

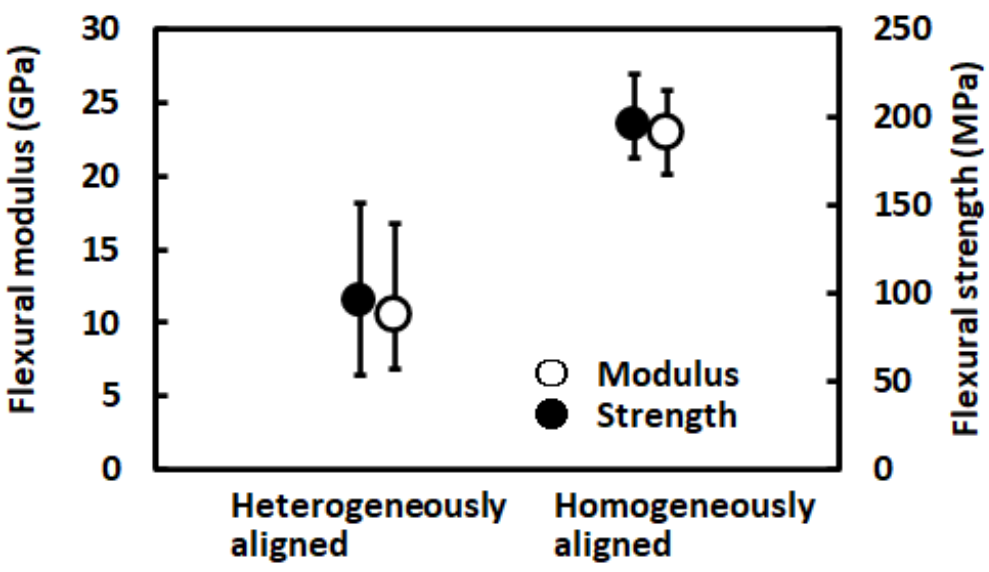

Fig. 7. Comparison of flexural modulus and strength values between heterogeneously and homogeneously aligned bamboo fiber composites

Figure 8 shows FCNF coated sheets with (a) homogeneously aligned bamboo and (b) heterogeneously aligned bamboo. Bamboo fibers in the homogeneous sheet were carefully aligned side by side without bamboo fibers crossing each other (one layer). In the heterogeneous sheet, the bamboo fibers were approximately unidirectionally aligned, but a small number of bamboo fibers were crossing other fibers. Figures 8(c) and 8(d) show cross-sectional views of the laminated composites using the sheets in Fig. 8(a) and 8(b), respectively. Each white part in the microstructures is bamboo fiber, while each black part is a gap, containing cavity and binder. As shown, the bamboo fibers in Fig. 8(c) were apparently deformed in the horizontal direction, that is, perpendicular to compressive direction. The bamboo fibers were close to each other, and gaps among them were small due to the large deformation. Miki et al. (2017) reported that wood structure could be deformed largely by shear stress at high temperatures up to $180{ }^{\circ} \mathrm{C}$. Meanwhile, the 
bamboo fibers in Fig. 8(d) seemed to be in their original shape, and gaps among the fibers were wide. This difference in the fibers' gaps was caused by different fiber deformation. That is, the crossed fibers in Fig. 8(a) is considered to inhibit fibers deformation. Inadequate fiber deformation creates gaps, which cause insufficient contact area between fibers and binders, resulting in weak force transmission in the fiber-reinforced composites. This is the reason why the homogeneously aligned fibers' composites showed higher mechanical properties (two times higher) than did the heterogeneously aligned fibers' composites. Especially in composites with a high percentage of natural fibers, the fiber deformation can be an important factor, due to the contact area depending on the gaps among the fibers.

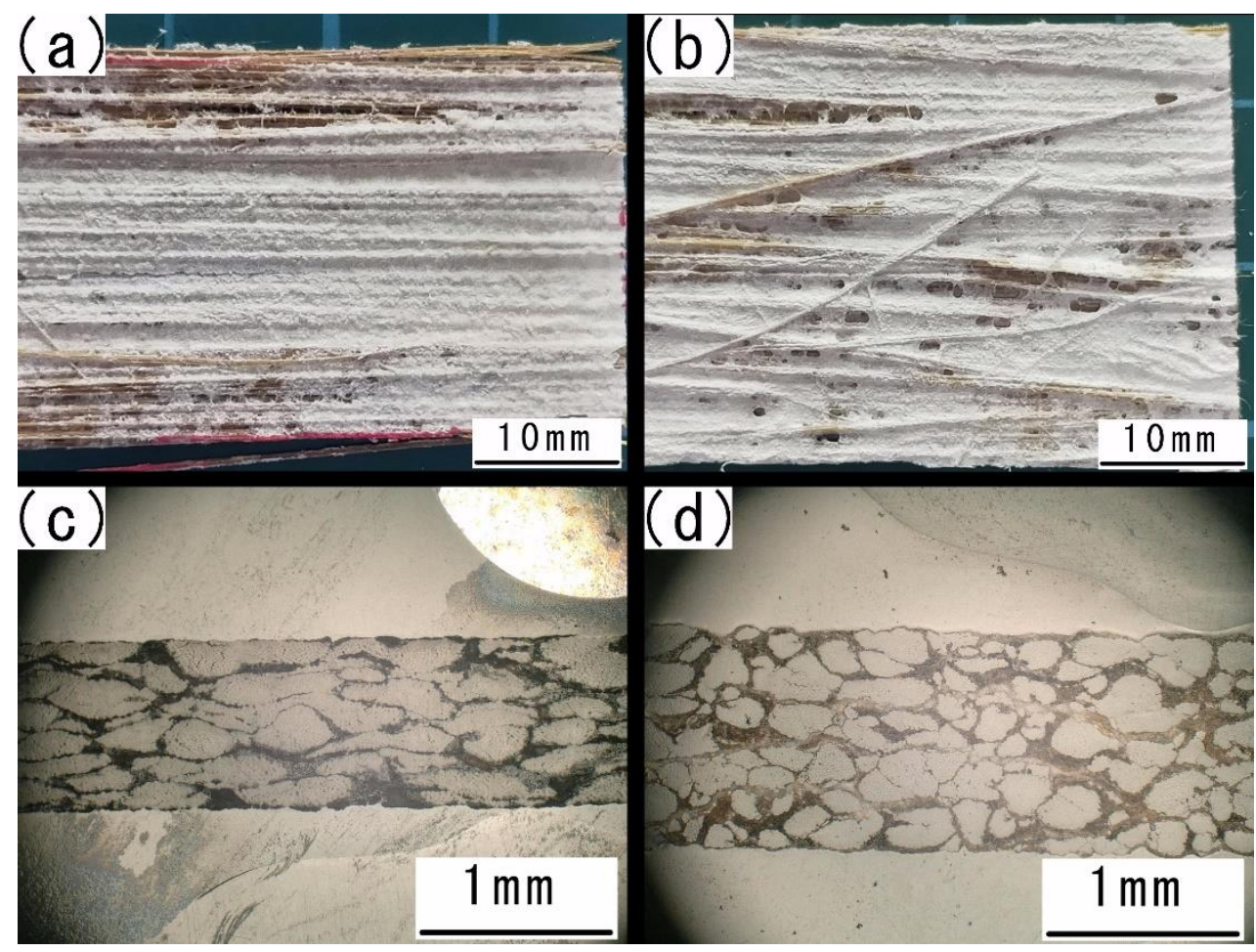

Fig. 8. (a) Homogeneously aligned bamboo fiber sheet after FCNF coating, (b) heterogeneously aligned sheet, (c) the cross-section microstructure of the composites using (a) sheets, and (d) cross-section microstructure of the composites using (b) sheets

Figure 9 shows relationships between hot-pressing temperature and flexural modulus and strength in the laminated FCNF-bamboo composites. Seven fabrication temperatures were investigated in the range of 150 to $270{ }^{\circ} \mathrm{C}$. Both flexural modulus and flexural strength were highest at $250{ }^{\circ} \mathrm{C}$. At $270{ }^{\circ} \mathrm{C}$, the surfaces of the bamboo composites became charred and black. The apparent change in the fiber color was reported as thermal degradation and decreased mechanical properties in previous studies (Sefat and Shibata 2020). In such cases, some hydrocarbons remaining in the fibers interact with one another or among water, pectin, hemicellulose, and non-crystalline celluloses, as suggested by Bourmaud et al. (2016). Thus, $250{ }^{\circ} \mathrm{C}$ was found to be the optimal temperature. Though $250{ }^{\circ} \mathrm{C}$ is not needed to cause chemical reaction of epoxy groups, these high temperature is enough to get hemicellulose chemistry to become active, potentially leading to crosslinking. Above this temperature, thermal degradation of natural fibers occurs. 


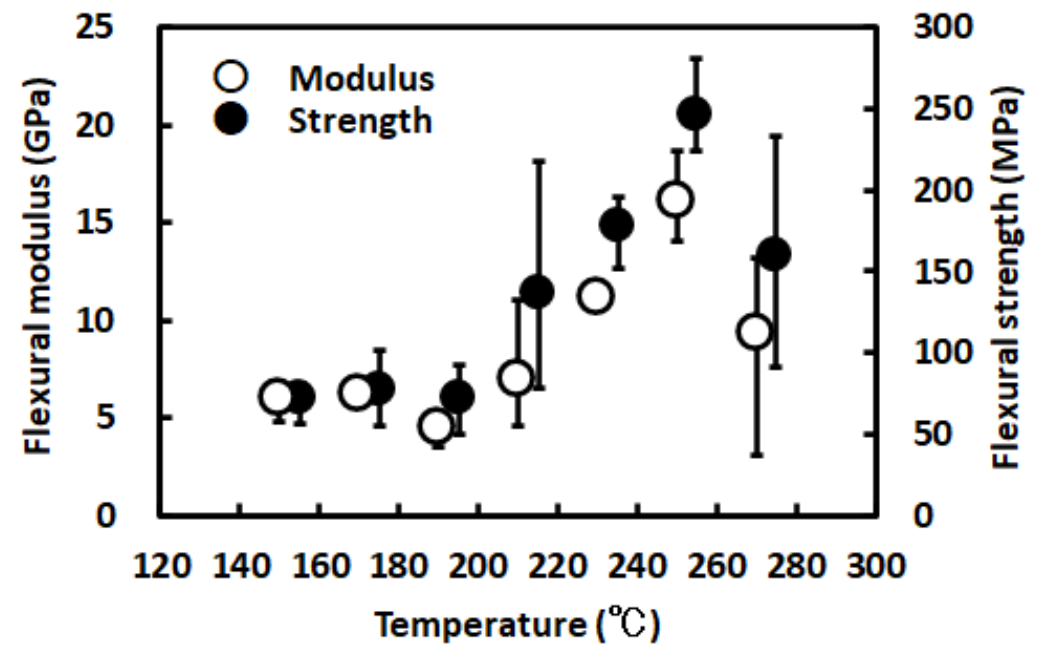

Fig. 9. Relationships between hot-pressing temperature and flexural modulus and strength in laminated FCNF composites

\section{CONCLUSIONS}

1. Three types of binders, 9,9-bis(aryl)fluorene-modified cellulose nanofiber (FCNF), cellulose nanofiber $(\mathrm{CNF})$, and crushed bamboo fiber $(\mathrm{CBF})$, were used to fabricate bamboo fiber composites. The FCNF-bamboo composites had the highest flexural strength and modulus. This result was estimated to the strong interaction between the binder and the fibers and also among the FCNF, which has epoxy groups that chemically interact with each other.

2. The flexural modulus and strength of the composites with homogeneously aligned bamboo fibers were two times higher than those of the composites with heterogeneously aligned fibers. The homogeneously aligned bamboo fibers dramatically deformed, as the fibers did not cross each other. Fiber deformation narrows the gaps among the fibers, resulting in high flexural modulus and strength.

3. There were considerable variations in the flexural modulus and flexural strength of the composites at different hot-pressing temperatures. This indicated that the FCNF has optimal chemical reaction temperature. However, above $250{ }^{\circ} \mathrm{C}$, the flexural modulus and strength decreased due to thermal degradation of the natural fibers.

\section{REFERENCES CITED}

Amada, S., Ichikawa, Y., Munekata, T., Nagase, Y., and Shimizu, H. (1997). "Fiber texture and mechanical graded structure of bamboo," Composites Part B:

Engineering 28(1-2), 13-20. DOI: 10.1016/s1359-8368(96)00020-0

Beck, A. J., Hodzic, A., Soutis, C., and Wilson, C. W. (2011). "Influence of implementation of composite materials in civil aircraft industry on reduction of environmental pollution and greenhouse effect," IOP Conference Series: Materials Science and Engineering 26. DOI: 10.1088/1757-899X/26/1/012015 
Bourmaud, A., Le Duigou, A., Gourier, C., and Baley, C. (2016). "Influence of processing temperature on mechanical performance of unidirectional polyamide 11flax fibre composites," Industrial Crops and Products 84, 151-165. DOI: 10.1016/j.indcrop.2016.02.007

Imanishi, H., Soma, N., Yamashita, O., Miki, T., and Kanayama, K. (2005). "Effect of production conditions of wood powder on bending properties of wood powder molding material without adhesive," JSME International Journal, Series A: Solid Mechanics and Material Engineering 48(4), 432-436. DOI: 10.1299/jsmea.48.432

ISO 178 (2010). "Plastics — Determination of flexural properties," International Organization for Standardization, Geneva, Switzerland.

Miki, T., Nakaya, R., Seki, M., Tanaka, S., Sobue, N., Shigematsu, I., and Kanayama, K. (2017). "Large deformability derived from a cell-cell slip mechanism in intercellular regions of solid wood," Acta Mechanica 228(8), 2751-2758. DOI: 10.1007/s00707015-1523-z

Netravali, A. N. (2019). "Advanced green composites: New directions," Materials Today: Proceedings 8, 832-838. DOI: 10.1016/j.matpr.2019.02.025

Nishino, T., and Arimoto, N. (2007). "All-cellulose composite prepared by selective dissolving of fiber surface," Biomacromolecules 8(9), 2712-2716. DOI: $10.1021 / \mathrm{bm} 0703416$

Nishino, T., Matsuda, I., and Hirao, K. (2004). "All-cellulose composite," Macromolecules 37(20), 7683-7687. DOI: 10.1021/ma049300h

Scholz, M.-S., Blanchfield, J. P., Bloom, L. D., Coburn, B. H., Elkington, M., Fuller, J. D., Gilbert, M. E., Muflahi, S. A., Pernice, M. F., Rae, S. I., et al. (2011). "The use of composite materials in modern orthopaedic medicine and prosthetic devices: A review," Composites Science and Technology 71(16), 1791-1803. DOI: 10.1016/j.compscitech.2011.08.017

Sefat, K. M., and Shibata, S. (2020). "Effect of removing sucrose and moisture in bagasse fibers on improvement of limit of processing temperature in bagasse-polypropylene composites," BioResources 15(3), 5481-5488. DOI: 10.15376/biores.15.3.5481-5488

Shekar, H. S. S., and Ramachandra, M. (2018). "Green composites: A review," Materials Today: Proceedings 5(1), 2518-2526. DOI: 10.1016/j.matpr.2017.11.034

Shibata, S., Cao, Y., and Fukumoto, I. (2008). "Flexural modulus of the unidirectional and random composites made from biodegradable resin and bamboo and kenaf fibres," Composites Part A: Applied Science and Manufacturing 39(4), 640-646. DOI: 10.1016/j.compositesa.2007.10.021

Sugimoto, M., Yamada, M., Sato, H., and Tokumitsu, K. (2019). "Reinforcement of polyamide 6/66 with a 9,9'-bis(aryl)fluorene-modified cellulose nanofiber," Polymer Journal 51(11), 1189-1195. DOI: 10.1038/s41428-019-0238-8

Sun, Z. (2018). "Progress in the research and applications of natural fiber-reinforced polymer matrix composites," Science and Engineering of Composite Materials 25(5), 835-846. DOI: $10.1515 / \mathrm{secm}-2016-0072$

Takagi, H., and Takeichi, G. (2012). "Bamboo fiber reinforced binderless green composites from steam-exploded bamboo powder," International Journal of Modern Physics: Conference Series 6, 739-744. DOI: 10.1142/s2010194512004072

Article submitted: Jan. 19, 2021; Peer review completed: Feb. 21, 2021; Revised version received and accepted: March 24, 2021; Published: April 14, 2021.

DOI: 10.15376/biores.16.2.3907-3915 